\title{
Large scale molecular analysis of traditional European maize populations. Relationships with morphological variation
}

\author{
C. REBOURG $\dagger$, B. GOUESNARD $\$$ \& A. CHARCOSSET*† \\ †INRA-UPS-INAPG, Unité de recherches de Génétique Végétale, Ferme du Moulon, 91190 Gif sur Yvette, \\ France and $\ddagger I N R A$, Unité de recherches de Génétique et d'Amélioration des Plantes, Domaine de Melgueil, \\ 34130 Mauguio, France
}

\begin{abstract}
A representative sample of 130 European traditional maize populations was analysed for both their morphological and molecular variation. The morphological analysis of 19 variables revealed a significant variability. Correlation analysis allowed us to distinguish between traits affected by earliness (plant and ear height) and structural traits (plant architecture, grain structure). Two main morphological types could be distinguished. Molecular analyses were performed for 29 RFLP loci on DNA bulks. The number of alleles detected was high when compared to previous studies $(9.59$ alleles per locus). Genetic diversity was also high (0.55), with a strong differentiation between populations $\left(G_{\mathrm{ST}}\right.$ value of $\left.35.6 \%\right)$. A clear relationship between the genetic diversity of the populations and their agronomic performances was highlighted. Morphological and molecular distances showed a tendency towards a triangular relationship. We therefore considered a two-phase process to be the most efficient approach for the classification of genetic resources: firstly, a molecular study to define groups of genetically close populations, and secondly a morphological description of populations from each group. In our European collection, this approach allowed us to separate the populations from Northern and Southern Europe and to define six groups of genetically close populations, comparable to European races. This study opens new prospects concerning the molecular analysis of very large collections of genetic resources, hitherto limited by the necessity of individual analyses, and proposes a first molecular classification of European maize germplasm.
\end{abstract}

Keywords: classification, European populations, genetic diversity, morphological variation, RFLP, Zea mays L.

\section{Introduction}

Starting from early domestication in Mexico, maize was introduced into many regions worldwide, becoming adapted to highly contrasting climates and agronomic conditions. Its is now clearly established that it was first introduced into Europe following the discovery of the New World in 1492. Contrasting variety types were then progressively cultivated in several European regions. After the Second World War, maize hybrids rapidly replaced traditional populations in most European regions. In order to avoid loss of genetic variability, many maize collections were established in different countries. It is important to characterize the genetic diversity of these collections in order to optimize conservation and facilitate their use. Furthermore, this

*Correspondence. E-mail: charcos@moulon.inra.fr characterization is necessary for the historical understanding of the introduction of maize in Europe.

Morphological descriptions of some of these collections were carried out in the 1960s in Spain, Italy, Yugoslavia and Romania (see for review Brandolini, 1970). Thereafter, other authors reported descriptions of populations from Portugal (Costa-Rodrigues, 1971), France (Gouesnard et al., 1997) and northern Spain (Llauradó \& Moreno-Gonzalez, 1993). Several authors were also interested in classification of populations on a European scale. Nevertheless, the relevance of morphological characters for the classification of populations appears limited, particularly because of the effect of environment on the expression of characters. The evaluation of diversity at individual loci overcomes these problems. Historically, isoenzymatic markers were first used, and allowed the analysis of different samples of European populations (Salabounat \& Pernes, 1986; 
Geric et al., 1989; Lefort-Buson et al., 1991; GarnierGéré, 1992; Llauradó et al., 1993; Revilla et al., 1998). Subsequently, DNA markers, particularly RFLPs, were used. This allowed the classification of maize inbred lines within heterotic groups (Melchinger et al., 1991; Livini et al., 1992; Messmer et al., 1992; Dubreuil et al., 1996). RFLP was more effective than isoenzymes for the analysis of maize populations (Dubreuil \& Charcosset, 1998). In order to use RFLPs for the analysis of large samples of populations, a DNA pooled-sampling strategy was developed (Dubreuil et al., 1999). This method was tested and proved efficient for the analysis of maize populations (Rebourg et al., 1999), therefore providing a convenient tool for the molecular analysis of large collections of populations.

The aim of this study was to evaluate the potential of this approach for obtaining a better understanding of European maize diversity. We analysed 131 European populations, carefully chosen to represent European origins, in order to define the most important European types. Besides the molecular analysis, these populations were evaluated for morphological and agronomic traits in order to compare molecular and phenotypic descriptions. This comparison allowed us to evaluate the best way to combine information in a comprehensive approach.

\section{Materials and methods}

\section{Genetic material}

We analysed a sample of 131 European maize populations. The INRA-PROMAÏS maize gene bank (Groupe Maïs DGAP-INRA \& PROMAÏS, 1994) supplied the majority, while other European institutes provided the others (Table 1). We tried to obtain a representative sample of populations for each country. Unfortunately, the sample was limited in some cases. The analysis was carried out on 37 South-Western European populations (36 from Spain and one from Portugal), 32 French populations, 16 Italian populations, 32 North-Eastern populations (13 from Germany, one from Switzerland, five from Czechoslovakia, eight from Poland, two from Austria and three from Ukraine) and 14 South-Eastern European populations (four from Hungary, three from Romania, four from Yugoslavia and three from Bulgaria). For some countries, we classified populations according to the region of origin (see 'origin' in Table 1).

\section{Morphological analyses}

In 1998, all the populations were sown at two INRA maize stations, Mauguio (Southern France near Montpellier) and Le Moulon (Northern France near
Paris). German population 23 did not sprout, so that 130 European populations were finally analysed. The populations were distributed into four earliness groups (based on preliminary observations performed in 1997) and randomized within groups. The experimental design had two replicates in each location, with a one-row plot of 25 plants each. The sowing density was 74000 plants per ha at Le Moulon and 58000 plants per ha at Mauguio.

We measured for each plot 26 morphological traits taken from 10 competitive plants, and from two kernels per ear. The kernel texture was noted on initial seeds with a scale from 1 for flint to 4 for dent. These primary traits were used to define 19 descriptors (Table 2). The flowering date was converted into accumulative degreedays as: $T T=\sum_{d=1}^{n}\left[\left(T X_{d}+T N_{d}\right) / 2 \quad T b\right]$, where $n$ is the number of days from sowing to flowering, $T X_{d}$ and $T N_{d}$ are, respectively, the maximum and minimum temperatures $\left({ }^{\circ} \mathrm{C}\right)$ of day $d, T b\left(6^{\circ} \mathrm{C}\right)$ is the critical temperature under which development is stopped (Bonhomme et al., 1994). The ear shape was estimated using the conicity index defined by Ordas \& De Ron (1988).

We performed analyses of variance in order to test the significance of variation between populations. These analyses allowed us to estimate genotypic and environmental variances, as well as the heritability of each morphological trait. A Principal Component Analysis was carried out on the phenotypic correlation matrix of the adjusted means of the populations for the 19 descriptors (Table 2), using the FACTOR procedure from SAS (SAS Institute, 1990). The matrix of distances between populations was calculated upon the standardized principal components with eigenvalue higher than one. We used the Euclidean distance called 'Mahalanobis generalized distance' defined by Goodman (1972) as:

$D_{i j}=\left[\sum_{k=1}^{k=K}\left(\frac{\left.Y_{i k} Y_{j k}\right)^{2}}{\lambda_{k}}\right)\right]^{1 / 2}$

where $Y_{i k}$ and $Y_{j k}$ are the values of principal component $k$ for populations $i$ and $j$, respectively, and $\lambda_{k}$ is the eigenvalue of principal component $k . K$ is the total number of principal components considered.

\section{Molecular analyses}

RFLP assays were carried out using a DNA pooledsampling strategy described more fully in Dubreuil et al. (1999) and Rebourg et al. (1999). Each population was represented by 30 plants, using two DNA bulks each extracted from leaf disks of 15 individuals. DNA was extracted according to Tai \& Tanksley (1990). DNA samples were digested separately with three restriction 


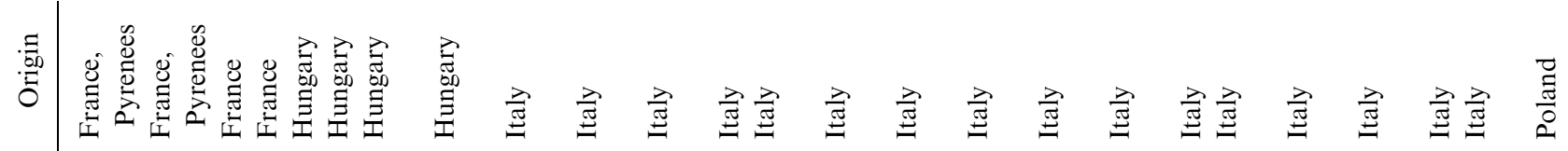

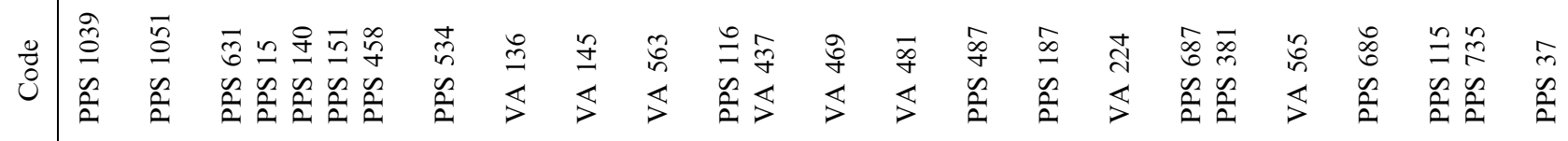

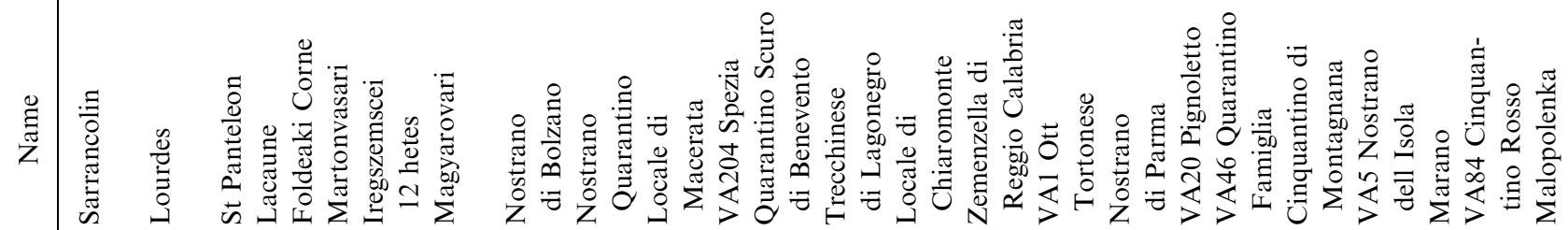

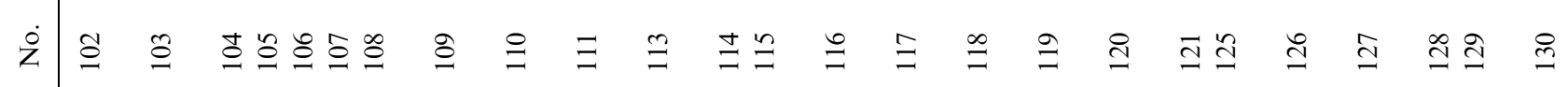

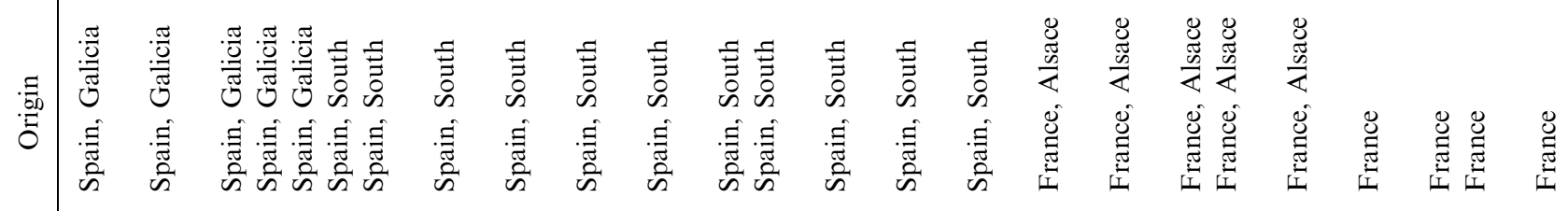

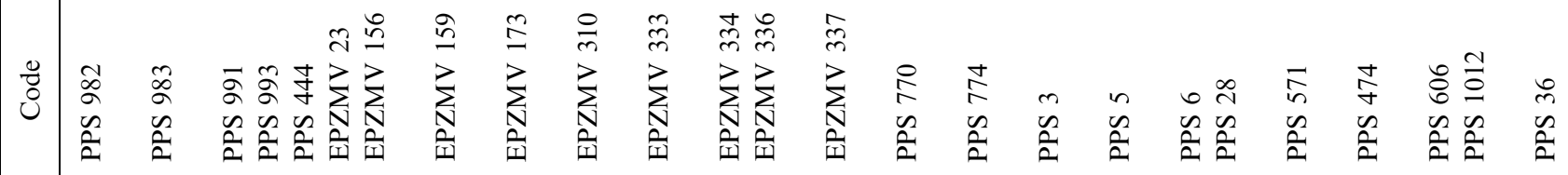

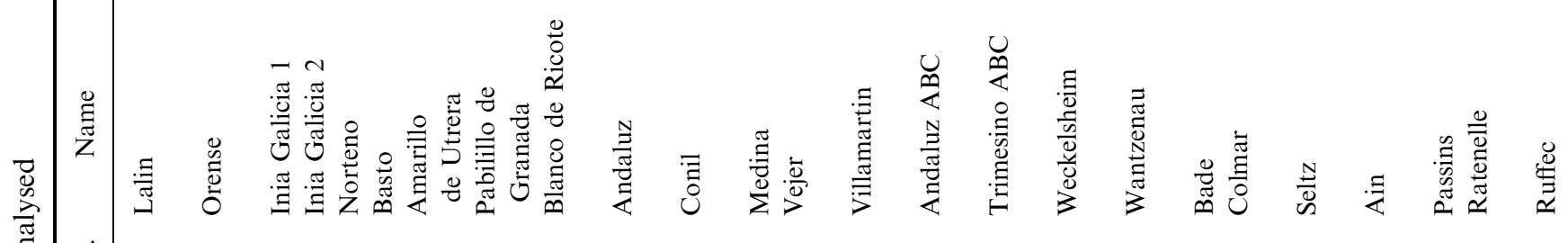

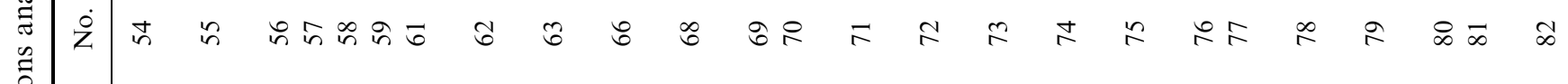

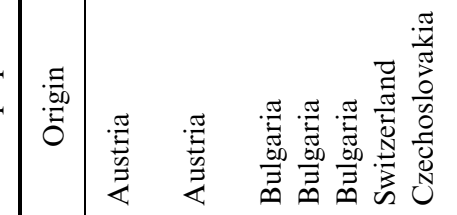

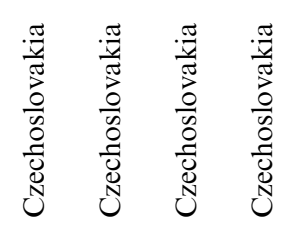

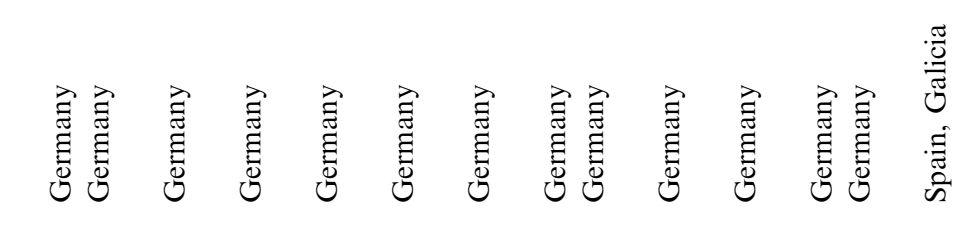

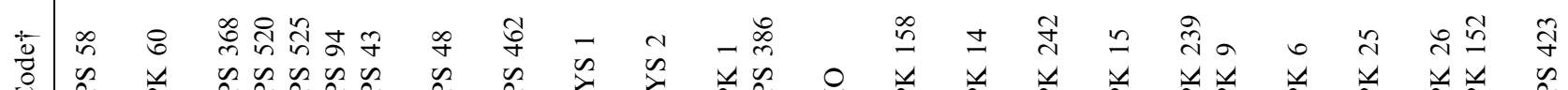

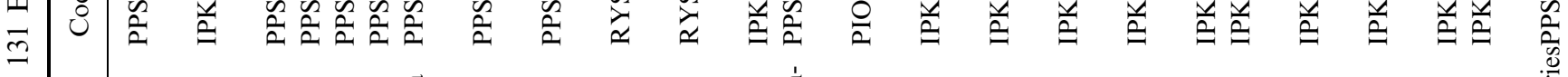

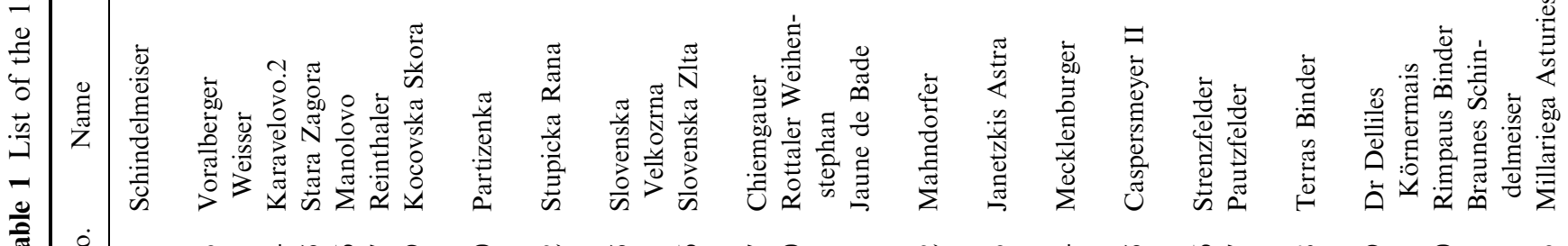

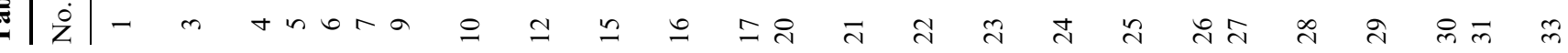




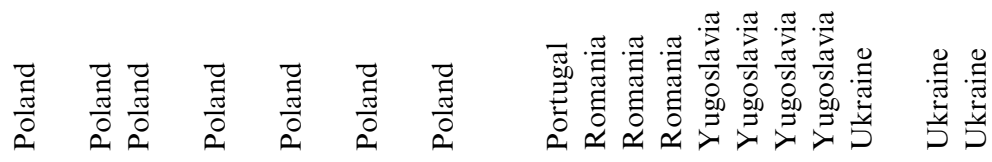

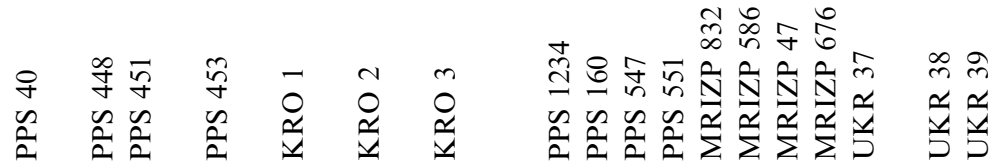

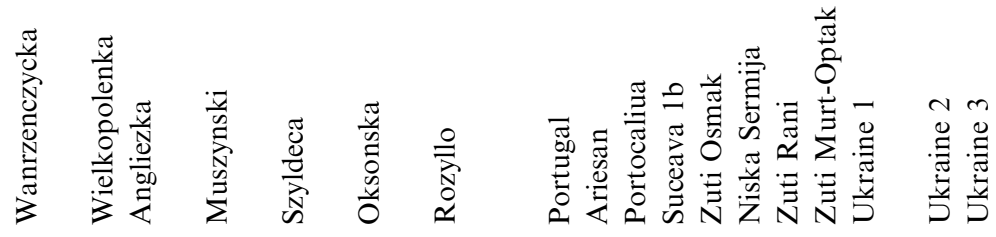

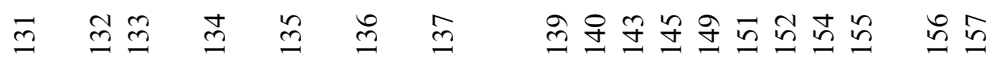

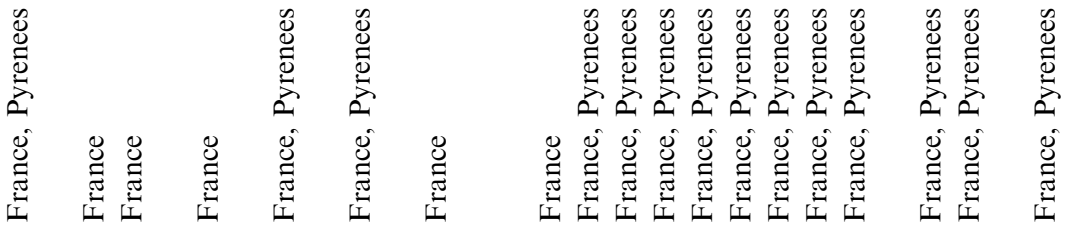

ఫ

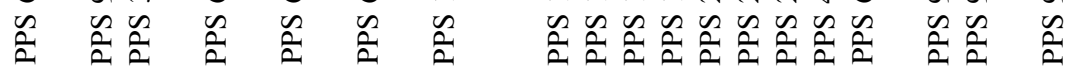

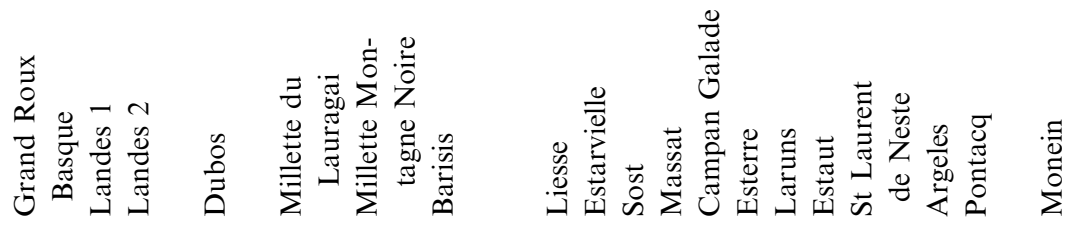

$\infty$ †

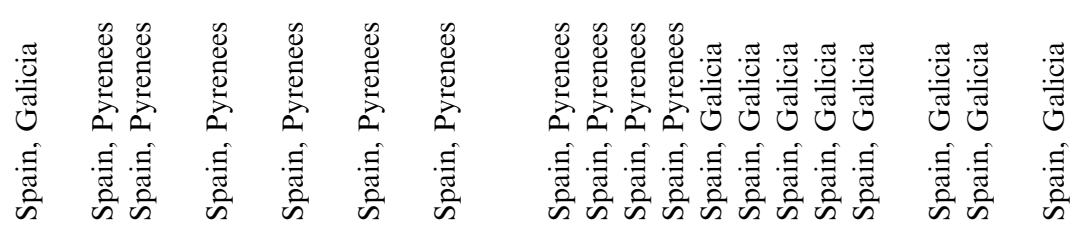

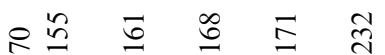

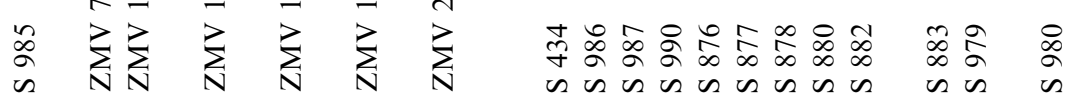

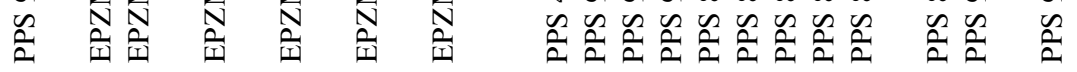

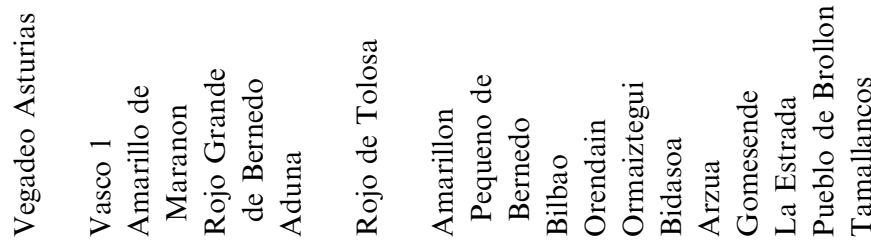

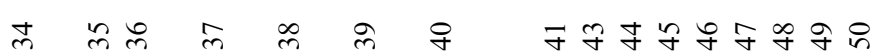

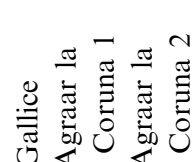

$\pi$ n

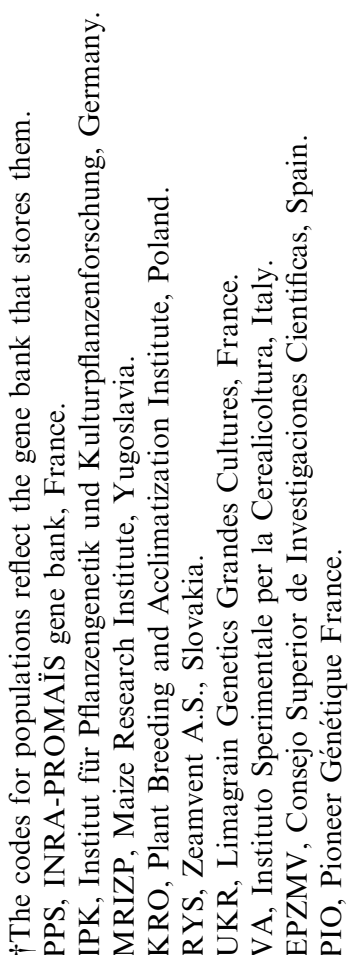

(C) The Genetics Society of Great Britain, Heredity, 86, 574-587. 


\begin{tabular}{lllcc}
\hline $\begin{array}{l}\text { Abbre- } \\
\text { viation }\end{array}$ & \multicolumn{1}{c}{ Morphological descriptor } & \multicolumn{1}{c}{ Range } & Mean & $h^{2}$ \\
\hline DDS & $\begin{array}{l}\text { Accumulative degree-days } \\
\text { to silking }\end{array}$ & $(563-1200.9)$ & 815.6 & 0.80 \\
& & $(82.4-206.7)$ & 164.2 & 0.71 \\
PHT & Plant height (cm) & $(20.9-129.3)$ & 72.9 & 0.83 \\
EHT & Ear height (cm) & $(86.8-179)$ & 138.4 & 0.75 \\
ELG & Ear length (mm) & $(8-21.1)$ & 11.8 & 0.87 \\
ERN & Ear row number & $(1.4-9)$ & 4.6 & 0.61 \\
ECI & Ear conicity index & $(23-49.8)$ & 38 & 0.85 \\
EDI & Ear diameter (mm) & $(355.3-675.1)$ & 560.2 & 0.77 \\
TLG & Tassel length (mm) & $(14.9-31.8)$ & 21.9 & 0.65 \\
BTL & Branched part/tassel length & $(27-49.9)$ & 38.2 & 0.58 \\
CTL & Central spike/tassel length & $(6.5-30.4)$ & 16.5 & 0.77 \\
PBN & Number of tassel primary & & & \\
& branches & $(6.4-11.8)$ & 9.2 & 0.82 \\
KLG & Kernel length (mm) & $(6.1-12.0)$ & 9.3 & 0.91 \\
KWI & Kernel width (mm) & $(105-425.4)$ & 287.6 & 0.79 \\
KWE & 1000 kernels weight (g) & $(131.3-596.8)$ & 261 & 0.76 \\
EKN & Ear kernel number & $(0-136)$ & 30.5 & 0.59 \\
TIL & Tillering percentage & $(0-25.6)$ & 8.6 & 0.62 \\
HLL & Husk-leaves length & $(0-95)$ & 4.1 & - \\
COB & Percentage of red cob & $(1-4)$ & 3.9 & - \\
TEX & Kernel texture (scale 1-4) & & & \\
\hline
\end{tabular}

Table 2 List of the 19 morphological descriptors for maize, with range, mean values and heritability enzymes (EcoRI, HindIII and Eco RV) and submitted to electrophoresis according to the Southern Blot procedure described by Sambrook et al. (1989). Separate DNA fragments were then vacuum transferred from gels to nylon membranes.

We used 15 UMC (University of Missouri, Colombia, MO) genomic probes, eight BNL (Brookhaven National Laboratory, Upton, NY) genomic probes, two NPI (Native Plants Inc., Pioneer Hi-Bred International) genomic probes and two cDNA clones. Seven probes were assayed with EcoRI, 13 with $H i n d I I I$, five with EcoRV and two with both EcoRI and HindIII, so that we finally analysed 29 probeenzyme combinations. DNA probes were radiolabelled with ${ }^{32} \mathrm{P}$-dCTP by random priming synthesis (Feinberg \& Volgenstein, 1983). Hybridization was performed as described by Church \& Gilbert (1984). After washing, nylon membranes were exposed to autoradiographic films.

All autoradiographic films were scanned. The ratio of the optical density of each band to total optical density of bands from the same lane was estimated using image analysis software (RFLPscan, Scanalytics). Probes were chosen that detected single loci and yielded a single band pattern, so that the ratio estimated for a band could be interpreted as the allelic frequency of an allele. For each population, we estimated allelic frequencies by the average frequencies of the two DNA pools representing this population (Fig. 1). The accuracy of this approach was established in preliminary experiments (Dubreuil et al., 1999).

Nei's unbiased genetic diversity (Nei, 1978) was computed for each locus $\left(H_{e l}\right)$ and for all the loci $\left(H_{e}\right)$ as

$H_{e}=\frac{1}{L} \sum_{l=1}^{l=L} H_{e l}$ and $H_{e l}=\frac{2 n_{l}}{2 n_{l}} \cdot 1 \cdot\left(1 \sum_{a=1}^{a=A_{l}}\left(p_{a l}\right)^{2}\right)$

where $p_{a l}$ is the frequency of allele $a$ at locus $l$ in the whole sample, $A_{l}$ is the number of alleles detected at this locus, $L$ is the total number of loci analysed and $n_{l}$ is the number of individuals characterized for locus $l$. Genetic diversity within a given population $i$ was estimated similarly at each locus $\left(H_{w l}^{i}\right)$ and for all loci $\left(H_{w}^{i}\right)$. In this case, $p_{a l}$ is the frequency of allele $a$ at locus $l$ within the population $i$ considered and $A_{l}$ is the number of alleles detected at this locus within this population. The mean of within-population diversity among the total sample was then estimated by $\bar{H}_{w}=\frac{1}{P} \sum_{i=1}^{i=P} H_{w}^{i}$ with $P$ the total number of populations. We evaluated genetic differentiation between populations as $G_{\mathrm{ST}}=D_{\mathrm{ST}} / H_{e}$ (Nei, 1973) where $D_{\mathrm{ST}}=H_{e} \quad \bar{H}_{w}$.

Genetic distances between populations were evaluated by the Modified Rogers' Distance (Rogers, 1972; Wright, 1978) defined as

$\left.M R D_{i j}^{2}=\frac{1}{L} \sum_{l=1}^{l=L} \sum_{a=1}^{a=A_{l}} \frac{1}{2} p_{a l}^{i} \quad p_{a l}^{j}\right)^{2}$ 
Fig. 1 Image of autoradiography resulting from hybridization of maize DNA digested by EcoRI with probe BNL5.09. Image analysis software allowed us to estimate allelic frequencies in each DNA pool extracted from one population (see example of population 68 ). The average frequencies in the two DNA pools are computed to estimate allelic frequencies within the population.

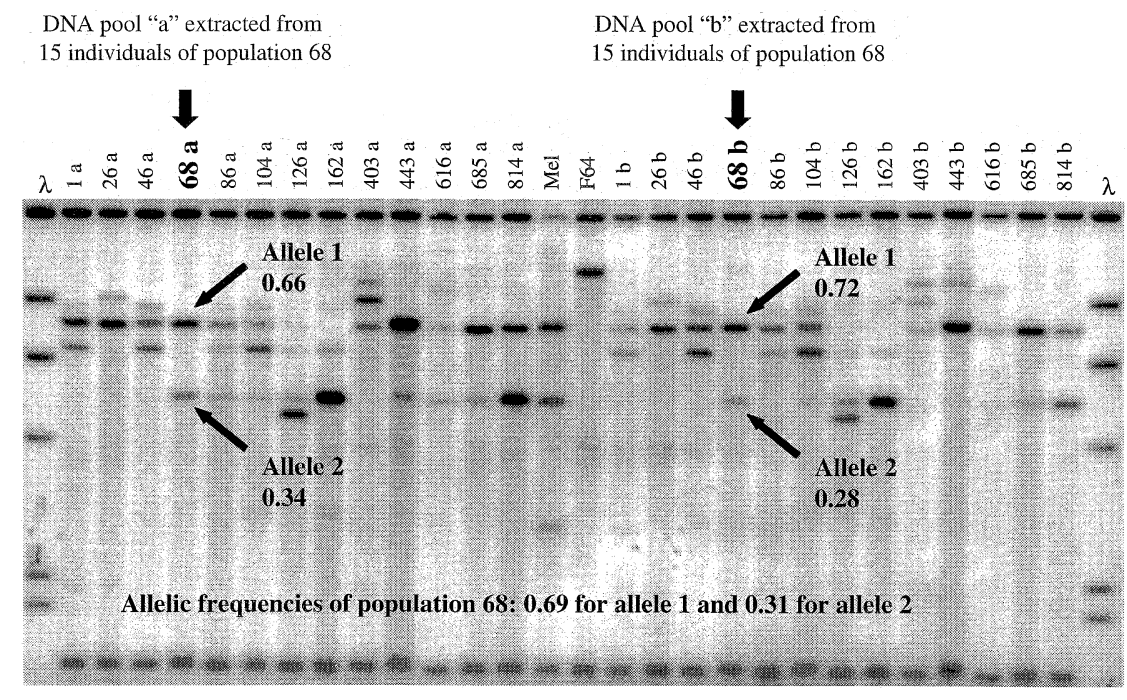

where $p_{a l}^{i}$ and $p_{a l}^{j}$ are the frequencies of allele $a$ at locus $l$ within populations $i$ and $j$, respectively, $A_{l}$ is the number of alleles detected at this locus $l$ and $L$ is the total number of loci analysed. We carried out a Ward's hierarchical ascendant classification (Ward, 1963) using the CLUSTER procedure from SAS (SAS Institute, 1990).

\section{Results}

\section{Morphological variation: distribution of variables}

Populations displayed dramatic variation for earliness, plant architecture traits, tassel traits, and ear and kernel characteristics, with the exception of kernel texture and cob colour that were, respectively, flint and white for most accessions. Consequently, high heritability values were observed for most traits (Table 2). Relationships between traits were investigated using graphs, correlation coefficient estimation and principal component analysis. The first four principal components (PC) accounted for $70.6 \%$ of the total variation (Table 3$)$. In the first PC $(28.2 \%)$, the most important traits were earliness and correlated traits (plant height and ear height, number of tassel primary branches). Ear diameter and kernel length also appeared important. In the second PC $(19.2 \%)$, predominant traits were the ear length, correlated with the tassel length, the kernel width and associated traits (kernel weight and number of ear rows). The third PC (14\%) described variation in the traits relating to the shape of ear (ear length and conicity), plant architecture (husk-leaf length and tillering) and ear kernel number. In the fourth PC $(9.2 \%)$, predominant traits were the proportions of central spike and branched part in total tassel length.
Table 3 Eigenvectors, eigenvalues and accumulated variation of the first four principal components (PC) from the correlation matrix based on maize population means

\begin{tabular}{lrrrr}
\hline & PC1 & PC2 & PC3 & PC4 \\
\hline DDS & -0.73 & 0.05 & -0.32 & -0.26 \\
PHT & -0.77 & 0.34 & -0.21 & -0.06 \\
EHT & -0.88 & 0.06 & -0.06 & -0.17 \\
ELG & -0.17 & 0.58 & -0.62 & -0.06 \\
ERN & -0.51 & -0.66 & -0.19 & 0.29 \\
ECI & -0.37 & -0.35 & 0.66 & 0.15 \\
EDI & -0.69 & 0.18 & 0.30 & 0.40 \\
TLG & -0.20 & 0.69 & -0.46 & 0.19 \\
BTL & -0.47 & 0.04 & -0.04 & -0.78 \\
CTL & -0.33 & -0.06 & -0.26 & 0.60 \\
PBN & -0.73 & -0.27 & -0.20 & -0.38 \\
KLG & -0.73 & 0.44 & 0.25 & 0.18 \\
KWI & -0.03 & 0.90 & 0.37 & 0.02 \\
KWE & -0.23 & 0.81 & 0.49 & 0.08 \\
EKN & -0.55 & -0.42 & -0.52 & 0.27 \\
TIL & 0.48 & 0.26 & -0.48 & 0.03 \\
HLL & 0.46 & 0.32 & -0.55 & 0.20 \\
COB & -0.32 & -0.07 & -0.04 & 0.23 \\
TEX & 0.48 & 0.12 & -0.10 & -0.14 \\
Eigenvalue & 5.37 & 3.64 & 2.66 & 1.74 \\
Accumulated & 28.2 & 47.4 & 61.4 & 70.6 \\
variation $(\%)$ & & & & \\
\hline
\end{tabular}

\section{Morphological variation: variation among populations and geographical origins}

The 130 populations were plotted in a plane defined by the first two PC which accounted for $47.4 \%$ of the total variation (Fig. 2). This representation distinguished different groups with particular morphological characteristics and highlighted a relation between geographical 


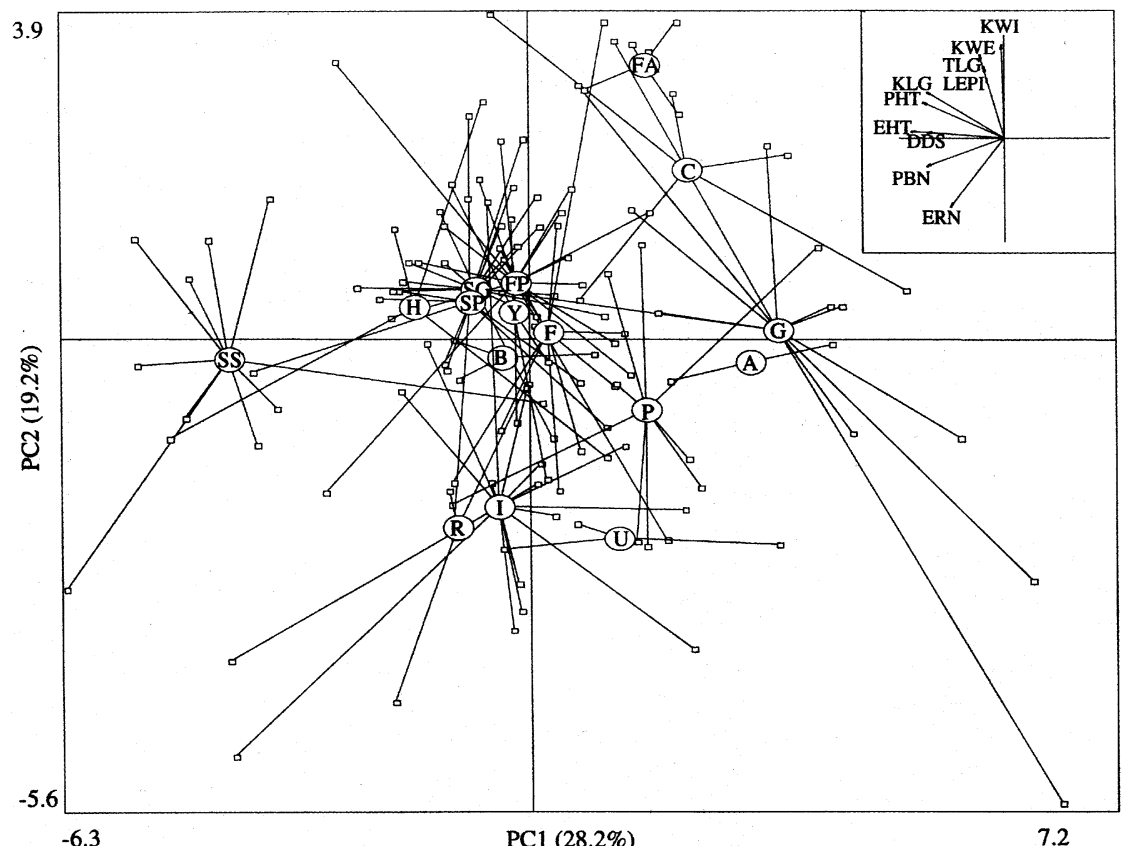

Fig. 2 Distribution of 130 European maize populations on the first two principal components $\mathrm{PC} 1$ and $\mathrm{PC} 2$ of the PCA performed for morphological data. Lines link each population to the barycentre of its geographical group, represented by letters: SS (Spain South), SP (Spain Pyrenees), SG (Spain Galicia), F (France, excepted Pyrenees and Alsace), FA (France Alsace), FP (France Pyrenees), I (Italy), G (Germany), A (Austria), P (Poland), H (Hungary), C (Czechoslovakia), B (Bulgaria), R (Romania), Y (Yugoslavia) and U (Ukraine). The most important variables for each Principal Component are represented. origins and morphological characteristics. Axis 1 separated populations according to precocity, plant height and ear height. The populations originating from the south of Spain (group SS, Fig. 2) were tall and late whereas the populations originating from North-Eastern Europe, mainly from Germany (group G), Austria (A) and Czechoslovakia (C) were shorter and earlier. Polish populations also appeared rather early. Axis 2 separated the populations according to kernel size and number of ear rows. It distinguished in particular the Italian populations (group I), as well as the Ukrainian (U) and Rumanian populations (R), which were characterized by many ear rows and very small kernels. The plot also illustrated the distinctiveness of French Alsatian populations (group FA) when compared to other French populations (groups F and FP).

\section{Molecular analysis: structure of polymorphism}

Number of alleles A total of 278 alleles was recorded within the collection for the 29 probe-enzyme combinations. The number of alleles appeared highly dependent on the locus and varied from three (UMC47/EcoRI and UMC132/EcoRV) to 18 (SC322/EcoRI and BNL6.06/HindIII) with an average value of 9.59 alleles per locus (Table 4). Within-population mean number of alleles varied between populations from 1.17 (German population 29) to 3.52 (Polish population 137) with an average value of 2.50 . Within-population number of alleles represented $26 \%$ of total number of alleles and therefore appeared restricted when compared to total variation. Hierarchical analysis of the number of alleles showed that differentiation (i) between geographical groups (i.e. South-Western Europe, France, Italy, North-Eastern Europe and South-Eastern Europe) (ii) between countries within groups and (iii) between populations within countries represent, respectively, $28 \%, 10 \%$ and $36 \%$ of total number of alleles. Those observations illustrate a clear structure for the number of alleles at these different levels.

Diversity Total diversity varied highly with the locus (Table 4) from 0.106 (BNL8.29/EcoRI) to 0.793 (SC322/EcoRI). For all loci, within-population diversity varied with the population from 0.051 (German population 29) to 0.489 (Polish population 137). Average values for total and within-population diversity were 0.550 and 0.354 , respectively. The corresponding $G_{\mathrm{ST}}$ value of 0.356 illustrated a high relative differentiation between populations, within-population variation representing $64 \%$ of total diversity.

Differentiation (i) between geographical groups (i.e. South-Western Europe, France, Italy, North-Eastern Europe and South-Eastern Europe) (ii) between countries within groups and (iii) between populations within countries represent, respectively, $6 \%, 3 \%$ and $27 \%$ of diversity.

\section{Molecular analysis: relationships between populations}

Cluster analysis of the molecular data first underlined a major differentiation between populations from Northern and Southern Europe (groups A and B in Fig. 3). 
Table 4 Number of alleles and diversity estimated at 29 RFLP loci in maize populations

\begin{tabular}{|c|c|c|c|c|c|c|}
\hline $\begin{array}{l}\text { Probe-enzyme } \\
\text { combination }\end{array}$ & $\begin{array}{l}\text { Chromosome } \\
\text { location }\end{array}$ & $\begin{array}{l}\text { Total no. } \\
\text { of alleles }\end{array}$ & $\begin{array}{c}\text { Average no. alleles } \\
\text { per population }\end{array}$ & $H_{e}$ & $\bar{H}_{w}$ & $G_{\mathrm{ST}}$ \\
\hline BNL5.09-EcoRI & 9 & 4 & 1.92 & 0.524 & 0.314 & 0.402 \\
\hline BNL8.29-EcoRI & 1 & 6 & 1.37 & 0.106 & 0.084 & 0.207 \\
\hline UMC10-EcoRI & 3 & 12 & 3.40 & 0.742 & 0.499 & 0.327 \\
\hline UMC103-HindIII & 8 & 8 & 1.88 & 0.291 & 0.233 & 0.199 \\
\hline UMC47-EcoRI & 4 & 3 & 1.72 & 0.233 & 0.162 & 0.305 \\
\hline UMC89-EcoRV & 8 & 5 & 2.11 & 0.653 & 0.465 & 0.288 \\
\hline BNL5.10-EcoRI & 9 & 11 & 3.40 & 0.486 & 0.258 & 0.468 \\
\hline UMC4-HindIII & 2 & 8 & 2.79 & 0.772 & 0.526 & 0.319 \\
\hline NPI270-EcoRI & 4 & 12 & 3.52 & 0.756 & 0.482 & 0.362 \\
\hline UMC15-HindIII & 4 & 15 & 3.05 & 0.645 & 0.466 & 0.278 \\
\hline BNL7.56-HindIII & 5 & 4 & 2.19 & 0.453 & 0.298 & 0.343 \\
\hline UMC161-EcoRI & 1 & 5 & 1.82 & 0.465 & 0.269 & 0.422 \\
\hline CSU81-HindIII & 7 & 8 & 2.04 & 0.508 & 0.337 & 0.336 \\
\hline BNL5.71-HindIII & 5 & 12 & 2.73 & 0.574 & 0.387 & 0.326 \\
\hline UMC132-EcoRV & 6 & 3 & 2.37 & 0.618 & 0.328 & 0.470 \\
\hline NPI406-HindIII & 1 & 4 & 1.73 & 0.343 & 0.184 & 0.464 \\
\hline $\mathrm{SC} 322-E c o \mathrm{RI}$ & 5 & 18 & 3.5 & 0.793 & 0.523 & 0.341 \\
\hline BNL5.10-HindIII & 9 & 14 & 2.88 & 0.581 & 0.389 & 0.331 \\
\hline UMC60-EcoRV & 3 & 14 & 2.41 & 0.507 & 0.310 & 0.388 \\
\hline UMC85-HindIII & 6 & 11 & 2.52 & 0.689 & 0.417 & 0.395 \\
\hline BNL6.06-HindIII & 3 & 18 & 3.85 & 0.784 & 0.524 & 0.332 \\
\hline
\end{tabular}

$H_{e}$, total genetic diversity at each locus $l$.

$\bar{H}_{w}$, average within-population genetic diversity for locus $l$.

$G_{\mathrm{ST}}$, relative differentiation between populations for locus $l$.

Group A included primarily populations of the North of Europe, i.e. the populations from France (centre) and Alsace, from Germany, Austria, Switzerland, Poland, Ukraine, Czechoslovakia, Hungary and Rumania. It was divided into two groups A1 and A2. The A1 group included mainly the German and Alsatian populations, referred to as 'German Flint'. The group A2 was called 'North-Eastern European Flint'. Group B consisted of populations originating from lower latitudes, i.e. populations from Spain, from the Pyrenees, from Italy or from Bulgaria. It was separated into two subgroups B1 and B2. The group B1 itself regrouped two sets: the 'Italian Orange Flint' (B1b) and various 'Southern European Flint' (group B1a, constituted of populations from southern Spain, Italy and Bulgaria). The B2 group is a very homogeneous group made up of the populations from Galicia and the
Pyrenees, the 'Pyrenees-Galicia Flint', except for a small subset (B2a) which we call the 'Czechoslovakian type'. This classification into six groups explained $42 \%$ of the variation observed.

\section{Comparison between molecular and morphological variation}

Relationship between heterozygosity and performance was investigated through the comparison of diversity and morphological traits or agronomic characteristics. Significant positive correlations were observed between diversity and the height of the plants or between diversity and the weight of the kernels per ear (Fig. 4).

The relationship between morphological and molecular distances was significant $\left(r=0.34^{* * *}\right)$. Analysis of the graph (Fig. 5) illustrates that low distances tend to

(C) The Genetics Society of Great Britain, Heredity, 86, 574-587. 


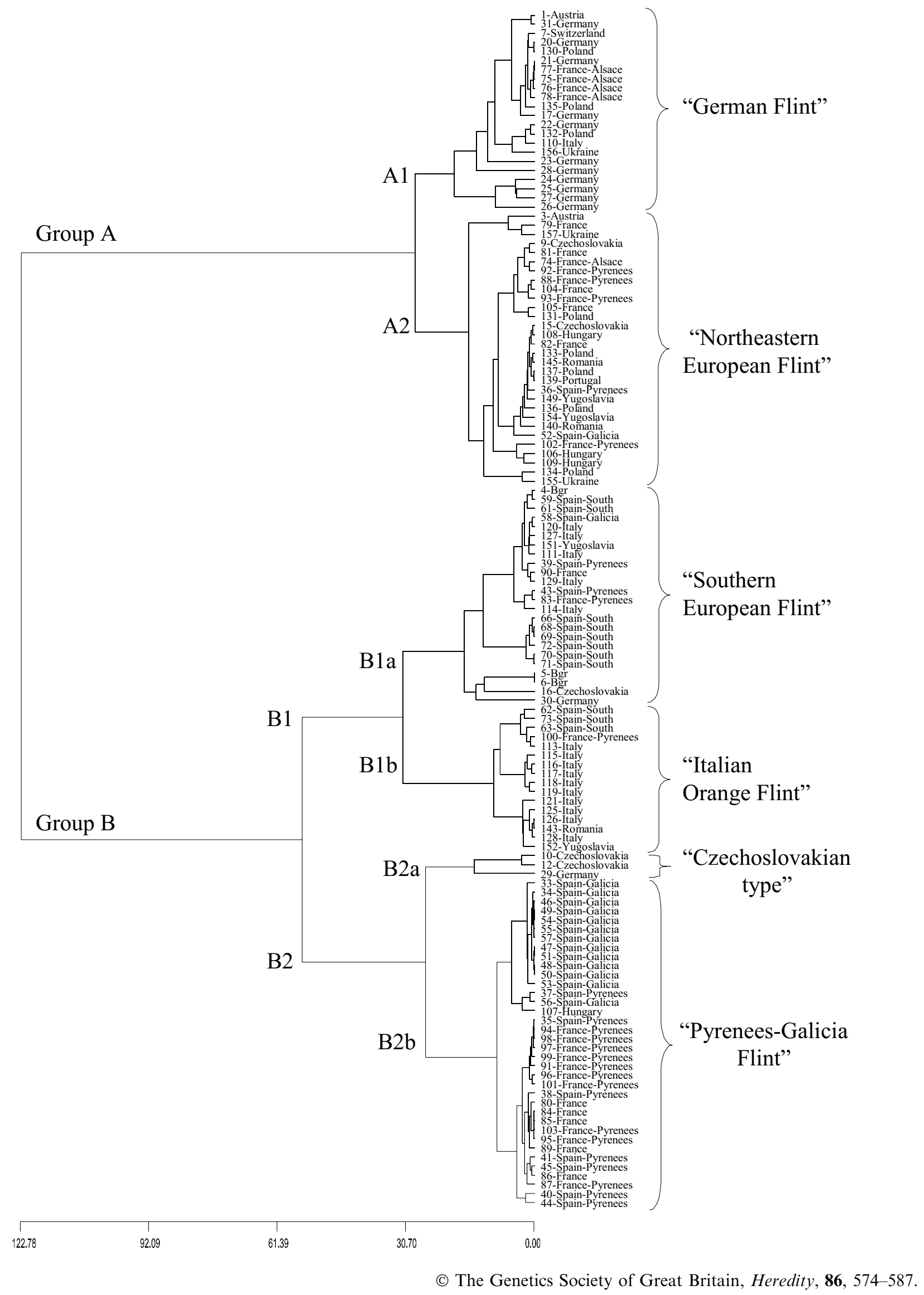


Fig. 3 Cluster analysis of 131 European maize populations based on RFLP allele frequencies. Ward's (1963) classification based on Rogers' (1972) distance.

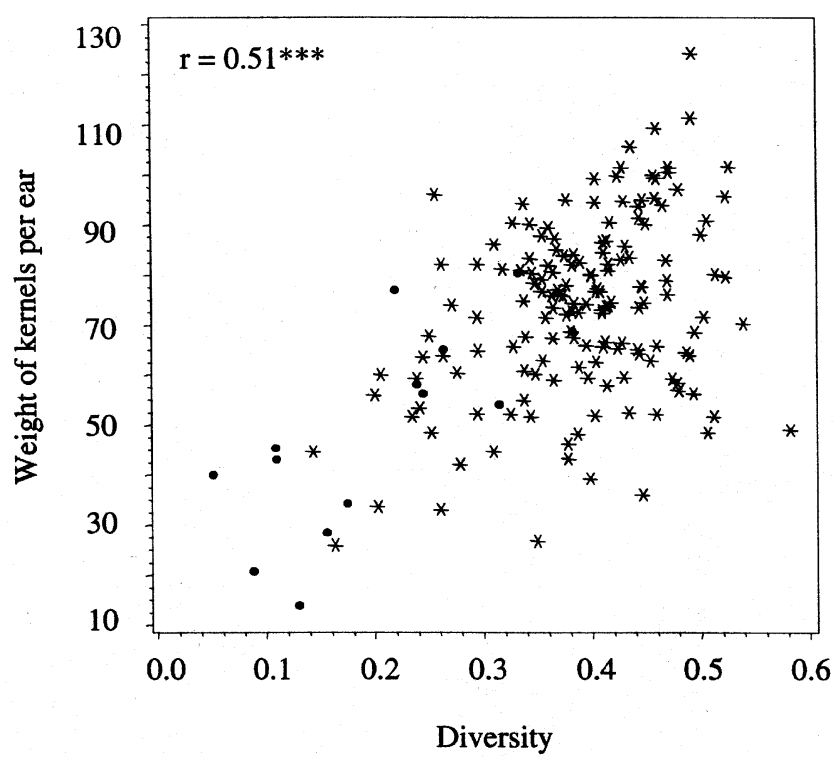

Fig. 4 Correlation between genetic diversity in maize and the weight of kernels per ear. The dots represent German and Austrian populations, the stars represent the other populations.

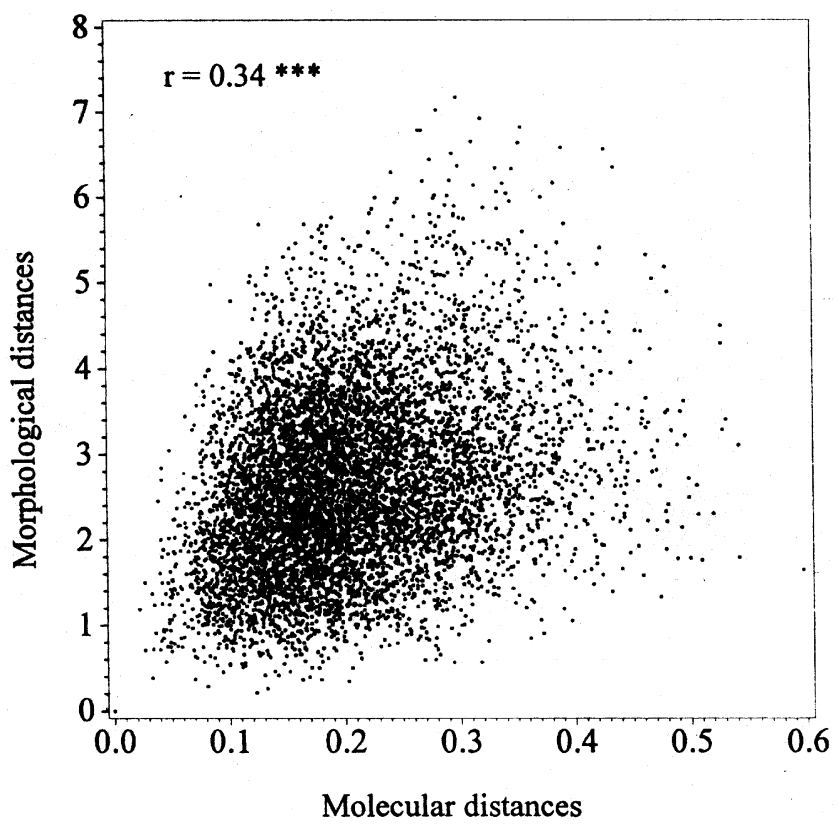

Fig. 5 Relationship between morphological and molecular distances in maize. be associated whereas the relationship decreases as the distance increases. Some asymmetry can be observed in the sense that morphological similarity can be associated with rather high molecular divergence whereas the reverse was not clearly observed.

\section{Discussion}

\section{Morphological variability of European germplasm}

This study first confirmed that traditional European maize populations display a large range of morphological variation with the remarkable exception of kernel texture (flint) and cob colour (white). High heritability values (higher than 0.6) were observed for most traits. The traits with the highest heritability were kernel width and number of ear rows (Table 2), as previously observed by Gouesnard et al. (1997) for French populations. The lowest heritability values were observed for tillering, husk leaf length and ear conicity index. The Principal Components Analysis (Table 3) revealed on the first PC a very strong effect of precocity on several morphological traits: plant height, ear height and number of tassel primary branches. This major role of earliness in phenotypic variation is consistent with observations in different samples of Spanish and French populations (Llauradó \& Moreno-Gonzalez, 1993; Gouesnard et al., 1997). Further components were determined by traits related to ear shape and kernel shape, plant structure (i.e. tillering and husk leaf length), and tassel traits. The second PC was mostly determined by ear length and tassel length (Table 3 ). These two traits were highly correlated, as were number of ear rows and number of tassel primary branches. These observations are consistent with an homology between ear and tassel, consequent to the origin of the ear from the feminization of a tillering tassel (Iltis, 1983).

The PCA allowed us to distinguish groups with different morphological characteristics. In particular, two morphological types were clearly distinct: (i) Southern Spain populations (group SS, Fig. 2) consisting of tall and late plants, with few tillers and short husk leaves, and (ii) German and Austrian populations (groups G and A) consisting of shorter and early plants, with many tillers and long husk leaves. Among French populations, we could separate Alsatian populations, consisting of early plants with cylindrical ears, from the others, as was previously observed by Gouesnard et al. (1997).

The importance of various variables in distance computation was balanced by standardizing the Principal Components. Nevertheless, earliness still played an important role in the classification that was obtained. This is questionable because this trait is highly heritable and can 
be easily modified by several cycles of selection (Hallauer, 1987, personal com.), so that maize populations with the same genetic background may have different earliness. As a consequence, morphological analysis does not seem fully appropriate for the classification of maize populations according to their genetic origin.

\section{Molecular diversity of European germplasm}

Despite being restricted to European germplasm, this study showed a high number of molecular alleles $(9.59$ alleles per locus) when compared to previous studies performed on either lines or populations. Dubreuil et al. (1996) found 5.9 alleles per locus in a large sample of 116 inbred lines and Rebourg et al. (1999) observed 6.6 alleles per locus in a smaller sample of 65 populations. Within-population number of alleles represented only $26 \%$ of the total number, illustrating a great contrast between populations. This was confirmed by a $G_{\mathrm{ST}}$ value of $36 \%$, which is very high when compared to the work of Hamrick \& Godt (1997), who observed values of $G_{\text {ST }}$ from $23 \%$ in allogamous cereals to $59 \%$ in autogamous cereals. It also can be noted that our $G_{\mathrm{ST}}$ value is higher than that previously found in smaller sets of populations by Dubreuil \& Charcosset (1998) and Rebourg et al. (1999). The significant differentiation between popula- tions results from the choice of the sample, representative of a great geographical area. An important part of diversity was also maintained between populations within countries ( $27 \%$ of total diversity), which implies limited gene flow.

Variation in the number of alleles and diversity within populations was examined in the light of genetic origins (Table 5). We observed a higher number of alleles in South-Western Europe (7.90 alleles per locus) than in North-Eastern (6.24) and South-Eastern Europe (5.72). Furthermore, populations from North-Eastern Europe encompassed a smaller average within-population number of alleles (2.02 allele per locus) than populations from South-Western Europe (2.78) and South-Eastern Europe (2.53). This variation of number of alleles between North and South of Europe was previously observed by Rebourg et al. (1999). It is consistent with the facts (i) that South-Western Europe is considered as being the site of most introductions of maize (Gay, 1984) and (ii) that adaptation of maize to Northern and Eastern Europe probably induced a loss of genetic variability, as a result of selection for tolerance to lower temperatures.

Populations with the lowest average number of alleles or diversity originated from Germany. This may be a consequence of an intrinsic narrow genetic basis of German germplasm. However, certain populations

Table 5 Partition of allele number and diversity among geographical groups of maize populations

\begin{tabular}{lccccc}
\hline Group & $\begin{array}{c}\text { No. of } \\
\text { populations }\end{array}$ & $\begin{array}{c}\text { Total allele } \\
\text { number† }\end{array}$ & $\begin{array}{c}\text { Average allele } \\
\text { number }\end{array}$ & $H_{e}$ & $G_{\text {ST }}$ \\
\hline Total sample & 131 & 9.59 & 2.49 & 0.550 & 0.356 \\
North-Eastern Europe & 32 & 6.24 & 2.02 & 0.501 & 0.477 \\
$\quad$ Austria & 2 & 2.14 & 1.55 & 0.314 & 0.411 \\
Switzerland & 1 & 2.28 & 2.28 & 0.367 & 0.000 \\
Czechoslovakia & 5 & 4.21 & 2.14 & 0.490 & 0.435 \\
Germany & 13 & 4.31 & 1.76 & 0.458 & 0.570 \\
Poland & 8 & 4.86 & 2.56 & 0.492 & 0.258 \\
Ukraine & 3 & 2.69 & 1.74 & 0.461 & 0.438 \\
South-Eastern Europe & 14 & 5.72 & 2.53 & 0.542 & 0.310 \\
Hungary & 3 & 4.59 & 2.67 & 0.549 & 0.246 \\
Rumania & 3 & 3.10 & 2.71 & 0.499 & 0.224 \\
Yugoslavia & 4 & 3.93 & 2.47 & 0.491 & 0.261 \\
Bulgaria & 3 & 5.45 & 2.25 & 0.413 & 0.213 \\
Italy & 16 & 6.66 & 2.30 & 0.485 & 0.322 \\
France & 32 & 7.90 & 2.72 & 0.512 & 0.248 \\
South-Western Europe & 37 & 7.86 & 2.78 & 0.545 & 0.251 \\
Spain & 36 & 3.07 & 3.77 & 0.544 & 0.254 \\
Portugal & 1 & & & 0.468 & 0.000 \\
\hline
\end{tabular}

$H_{e}$, total genetic diversity within the group.

$G_{\mathrm{ST}}$, relative differentiation between populations in the group.

$\dagger$ Average per locus.

tWithin-population allele number. 
appeared close to fixation for RFLP alleles (number of alleles down to 1.17 and diversity down to 0.051 ) and it seems more probable that they were multiplied in a manner that favoured inbreeding. Salabounat \& Pernes (1986) arrived to the same conclusion concerning some populations originating from Hungary or Czechoslovakia.

Investigation of the relationship between diversity and morphological traits shows that the performance of these populations is clearly affected by inbreeding depression (Fig. 4). On the other hand, no population displayed a very high number of alleles (maximum 3.5). As a whole, Fig. 4 suggests that the diversity of European maize populations is determined, at least partly, by an equilibrium between genetic drift on the one hand and selection of heterozygotes or allopollen advantage on the other. It clearly illustrates that drift generates in some cases a strong inbreeding depression, that strongly diminishes agronomic performance.

\section{Molecular classification of European populations}

We observed a tendency towards a triangular relationship between morphological distances and molecular distances (Fig. 5), showing that similar phenotypes can be produced in genetically distant populations. This observation is consistent with results on inbred lines and theoretical analyses (Burstin \& Charcosset, 1997; Dillmann et al., 1997). It supports the superiority of molecular data for defining groups of populations with similar origins. The best way to classify and describe genetic resources such as traditional maize populations, therefore appears to be a two-step process: first a classification based on molecular data, and secondly a morphological description of each group.

Following this method, we elaborated a classification that distinguishes six major groups that are consistent with the origins of the populations and their morphological characteristics described below.

'German Flint' These 22 populations (group A1, Fig. 3) are mainly from Germany or Alsace. They are early flowering and small. Tassels have little ramification. They have many tillers and long husk leaves. Their ears are long, fine and cylindrical, presenting 10 rows on average (from 8 to 14). These populations correspond to the $8-10$ row types highlighted by Leng et al. (1962) during the analysis of populations originating from Italy, Yugoslavia, Romania and Hungary. They present a morphological type near to that of Northern Flint described by Brown \& Anderson (1947). This group also includes some populations of the type 'broad ears with 8-12 rows' characterized by shorter and broader ears, but strongly resembling type '8-10 rows' (Edwards \& Leng, 1965).
'North-Eastern European Flint' These 30 populations (group A2, Fig. 3) are from very diverse origins, mainly from France, but also Spain, Portugal and several Eastern European countries (Poland, Hungary, Yugoslavia, Czechoslovakia, Ukraine). They are of intermediate earliness and have many tillers. Their ears are long, cylindrical and consist of a variable number of rows (8-18).

'Southern European Flint' These 24 populations (group B1a, Fig. 3) originate from various countries principally of Southern Europe (southern Spain, Italy, Bulgaria). They are late, tall, and have ramified tassels. They have few tillers and short husk leaves. The ears are large, conical, with 12 rows on average. The kernels are much lengthened but not very broad.

'Italian Orange Flint' This is a rather homogeneous group (group B1b, Fig. 3), made up of 16 populations mostly originating from Italy, with some others from southern Spain. The populations are late, with ramified tassels. They have few tillers and short husk leaves. The ears are short, conical, with many rows (from 8 to 22 , on average 13) and very small kernels. This type of population seems to correspond to the type 'flint with small kernels' defined by Leng et al. (1962) during the study of South-Eastern European corn.

'Czechoslovakian type' This group (group B2a, Fig. 3) includes only two Czechoslovakian and one German population. The populations are early, small, with poorly ramified tassels. They have many tillers and long husk leaves. The ears are fine, cylindrical and consist of eight rows with few kernels. The kernels are broad, but short. This is a rather peculiar group, as the populations present morphological characteristics close to the populations of the groups 'Germany' and 'North-Eastern Europe', but they are distantly related at the molecular level.

'Pyrenees-Galicia Flint' This group (group B2b, Fig. 3) consists of 36 populations. It can be divided into two very homogeneous subgroups, one comprising the populations from Galicia, the other populations from the Pyrenees (French and Spanish) and other regions from France. The populations are early, but tall, and have short husk leaves. Their ears are short, conical, and very broad. They have an average number of 12 rows (from 10 to 18) with very large kernels. During the morphological analysis of the collection of French populations, Gouesnard et al. (1997) also highlighted a 'Pyrenean type' made up of early populations with broad kernels. During a morphological analysis of 
Spanish populations, Llauradó \& Moreno-Gonzalez (1993) classified the populations of northern Spain into only one race. By isoenzyme analysis, Llauradó et al. (1993) observed differences between Galicia and Cantabria. The populations analysed here originate from Galicia and Asturia, and are close at the molecular level. Similar populations were described in Portugal under the name of 'Conico' (Costa-Rodrigues, 1971).

\section{Conclusion}

This study illustrates the potential of molecular markers for the large scale analysis of genetic resource collections, in addition to morphological descriptors. The molecular analyses were performed by RFLP analysis of DNA bulks. This technique enabled us to highlight in this European collection a great genetic diversity and a strong differentiation between populations. The analysis of bulks does not allow the estimation of heterozygote frequency, which can be prejudicial for population genetics approaches. However, it remains to date the most effective tool for the RFLP diversity analysis of a significant number of populations.

The main limitation of this technique is the number of suitable RFLP probes. It would therefore be interesting to develop other markers suitable for the analysis of DNA bulks. In particular, the use of the microsatellite markers could be interesting because of their higher polymorphism, lower cost and potential for automation. These markers should also facilitate the definition of an international 'standard'. This would help to compare results from analyses performed in different laboratories. Ultimately, it would also be interesting to develop markers within genes of known function.

The methodology which appeared as the most effective to us for the analysis and the description of large collections of genetic resources, was a two-phase process: firstly, a molecular study leading to the definition of closely related groups at the DNA level; secondly a morphological study and description of the populations from the various genetic groups. We could define six genetic groups for European maize populations. These different groups can be referred as European races. Nevertheless, some questions remain, in particular for countries which were under-represented, or not represented at all in our study. In particular, it would be interesting to gain information concerning the Portuguese material, and to study other populations from Eastern Europe to better characterize the material here defined here by only three populations. A project associating various European laboratories and coordinated by INRA at Montpellier is currently under way (web page http://meleze.ensam.inra.fr/gap/resgen88). In addition, the various European races defined here, lead to questions about their origins. These races could result from a common origin and have diverged during the adaptation of maize in Europe. However, it seems more probable that they have different origins. The joint analysis of European and American germplasm should make it possible to identify American races closest to the various European races, and to make conclusions about the introduction of maize into Europe (Rebourg, 2000).

\section{Acknowledgements}

We are grateful to Marielle Merlino, Valérie Combes, and Fabrice Dumas from INRA at Gif sur Yvette for their expert technical assistance for molecular analyses, and to Jacques Dallard, Philippe Noël, J.G. Tourrière, and Philippe Marsal from INRA at Montpellier and Daniel Jolivot, Denis Coubriche and Philippe Jamin from INRA at Gif sur Yvette for morphological descriptions. We are grateful to Pierre Dubreuil for his critical reading of the manuscript. Part of this work was supported by the French Ministry of Agriculture and the PROMAIIS association members involved in this research: Asgrow France, Cargill Semences, Caussades Semences, COOP de Pau, Novartis, Limagrain Genetics, Pioneer Génétique, S.D.M.E. and Verneuil Recherche.

\section{References}

BONHOMME, R., DERIEUX, M. AND EDMEADES, G. O. 1994. Flowering of diverse maize cultivars in relation to temperature and photoperiod in multilocation field trials. Crop Sci., 34, 156-164.

BRANDOLINI, A. 1970. Razze Europee di Mais. Maydica, 15, 5-27.

BROWN, W. L. AND ANDERSON, E. 1947. The Northern flint corns. Ann. Mo. Bot. Gard., 34, 1-28.

BURSTIN, J. AND CHARCOSSET, A. 1997. Relationship between phenotypic and marker distances: theoretical and experimental investigations. Heredity, 79, 477-483.

CHURCH, G. M. AND GILBERT, W. 1984. Genomic sequencing. Proc. Natl. Acad. Sci. U.S.A., 81, 1991-1995.

COSTA-Rodrigues, L. 1971. Races of maize in Portugal. Agron Lusit., 31, 239-284.

DILlmANN, C., BAR-HEN, A., GUÉRIN, D., CHARCOSSET, A. ET $A L$. 1997. Comparison of RFLP and morphological distances between maize Zea mays L. inbred lines. Consequences for germplasm protection purposes. Theor. Appl. Genet., 95, 92-102.

DUBREUIL, P. AND CHARCOSSET, A. 1998. Genetic diversity within and among maize populations: a comparison between isozyme and nuclear RFLP loci. Theor. Appl. Genet., 96, $577-587$.

Dubreuil, P., DUfour, P., KReJCI, E., CAUSSE, M., DE VIENNE, D. $E T A L$. 1996. Organization of RFLP diversity among inbred lines of maize representing the most significant heterotic groups. Crop Sci., 36, 790-799. 
DUbreuil, P., REBOURG, C., MERLino, M. AND CHARCOSSET, A. 1999. The DNA-pooled sampling strategy for estimating the RFLP diversity of maize populations. Plant Mol. Biol. Report, 17, 123-138.

EDWARDS, R. J. AND LENG, E. R. 1965. Classification of some indigenous maize collections from southern and southeastern Europe. Euphytica, 14, 161-169.

FEINBERG, A. AND VOlgENSTEIN, B. 1983. A technique for radiolabelling DNA restriction endonuclease fragments to high specific activity. Analyt. Biochem., 132, 6-13.

GARNIER-GÉRÉ, P. 1992. Contribution à l'étude de la variabilité génétique inter-et intra-population chez le ma (Zea mays L.): Valorisation d'informations agronomiques et enzymatiques. Thèse de Doctorat, Institut National Agronomique ParisGrignon, Paris.

GAY, J.-P. 1984. Fabuleux maïs: histoire et avenir d'une plante. Association Générale de Producteurs de Maïs, Pau.

GERIC, I., ZLOKOLICA, M., GERIC, C. AND STUBER, C. W. 1989. Races and Populations of Maize in Yugoslavia. Isozyme Variation and Genetic Diversity. I.B.P.G.R., Rome.

Goodman, M. M. 1972. Distance analysis in biology. Syst. Zool., 21, 174-186.

GOUESNARD, B., DAllard, J., PANOUillé, A. AND Boyat, A. 1997. Classification of French maize populations based on morphological traits. Agronomie, 17, 491-498.

GROUPE MAÏS DGAP-INRA AND PROMAÏs. 1994. Cooperative programme for management and utilization of maize genetic resources. In: Balfourier, F. and Perretant, M. R. (eds) Evaluation and Exploitation of Genetic Resources Pre-breeding. Proceedings of the Genetic Resources of EUCARPIA, 15th-18th March 1994. Clermont-Ferrand, France.

HAMRICK, J. L. AND GODT, M. J. W. 1997. Allozyme diversity in cultivated crops. Crop Sci., 37, 26-30.

ILTIS, H. H. 1983. From teosinte to maize: the catastrophic sexual transmutation. Science, 222, 886-894.

LEFORT-BUSON, M., LAVERGNE, V., DAUDIN, J.-J., CHARCOSSET, A. ET AL. 1991. Genetic variability among populations of maize germplasm 2. Enzymatic polymorphism and its relationship to quantitative trait diversity. Maydica, 36, 237-246.

LENG, E. R., TAVCAR, A. AND TRIFUNOVIC, v. 1962. Maize of Southeastern Europe and its potential value in breeding programmes elsewhere. Euphytica, 11, 263-272.

LIVINI, C., AJMONE-MARSAN, P., MELCHINGER, A. E., MESSMER, M. M. ET AL. 1992. Genetic diversity of maize inbred lines within and among heterotic groups revealed by RFLPs. Theor. Appl. Genet., 84, 17-25.

LLAURADÓ, M. AND MORENO-GONZALEZ, J. 1993. Classification of Northern Spanish populations of maize by methods of numerical taxonomy. I. Morphological traits. Maydica, 38, $15-21$.

LLAURADÓ, M., MORENO-GONZALEZ, J. AND ARÚS, P. 1993. Classification of Northern Spanish populations of maize by methods of numerical taxonomy. II. Isozyme variation. Maydica, 38, 249-258.

MELChINGER, A. E., MESSMER, M. M., LEE, M., WOOdMAN, W. L. ET AL. 1991. Diversity and relationships among U.S. maize inbreds revealed by restriction fragment length polymorphisms. Crop Sci., 31, 669-678.

MESSMER, M. M., MELCHINGER, A. E., BOPPENMAIER, J., BRUNKLAUS-JUNG, E. ET AL. 1992. Relationships among early European maize inbreds. I: genetic diversity among flint and dent lines revealed by RFLPs. Crop Sci., 32, 1301-1309.

NEI, M. 1973. Analysis of gene diversity in subdivided populations. Proc. Natl. Acad. Sci. U.S.A., 70, 3321-3323.

NEI, M. 1978. Estimation of average heterozygosity and genetic distance from a small number of individuals. Genetics, $\mathbf{8 9}$, 583-590.

ORDAS, A. AND DE RON, A. M. 1988. A method to measure conicalness in maize. Maydica, 33, 261-267.

Rebourg, C. 2000. Diversité génétique de populations européennes et américaines de ma: Analyse moléculaire et morphologique. Thèse de doctorat, Université Paris XI, Orsay.

REBOURG, C., DUbreuil, P. AND ChARCosset, A. 1999. Genetic diversity among maize populations: bulk RFLP analysis of 65 accessions. Maydica, 44, 237-249.

ReVilla, P., Sengas, P., MALVAR, R. A., CARTEA, M. E. ET $A L$. 1998. Isozyme variation and historical relationships among the maize races of Spain. Maydica, 43, 175-182.

ROGERS, J. S. 1972. Measures of similarities and genetic distances. In: Wheeler, M. R. (ed.) Studies in Genetics VII, vol. 7213, pp. 145-153. University of Texas Publications.

SAlabounAt, M. AND PERneS, J. 1986. Enzyme polymorphisms within and between European maize populations. Maydica, 31, 269-278.

SAMBROOK, J., FRITSCH, E. F. AND MANIATIS, T. 1989. Molecular Cloning: A Laboratory Manual. Cold Spring Harbor Laboratory Press, Cold Spring Harbor, NY.

SAS INSTITUTE. 1990. SAS/STAT User's Guide. SAS Institute, Cary, NC.

TAI, T. H. AND TANKSLEY, S. D. 1990. A rapid and inexpensive method for isolation of total DNA from dehydrated plant tissue. Plant Mol. Biol. Report, 8, 297-303.

WARD, J. H. 1963. Hierarchical grouping to optimize an objective function. Am. Stat. Ass. J., 56, 236-244.

Wright, s. 1978. Evolution and Genetics of Populations. University Chicago Press, Chicago. 